\title{
In Vitro Antibacterial Activity of Unconjugated and Conjugated Bile Salts on Staphylococcus aureus
}

\author{
Thippeswamy H. Sannasiddappa ${ }^{1 *}$, Peter A. Lund ${ }^{2}$ and Simon R. Clarke ${ }^{1 *}$ \\ 'School of Biological Sciences, University of Reading, Reading, United Kingdom, ${ }^{2}$ Institute of Microbiology and Infection, \\ School of Biosciences, University of Birmingham, Birmingham, United Kingdom
}

\section{OPEN ACCESS}

Edited by:

Octavio Luiz Franco,

Universidade Católica de Brasilia,

Brazil

Reviewed by:

Armen Trchounian

Yerevan State University, Armenia

Adelaide Almeida,

University of Aveiro, Portugal

${ }^{*}$ Correspondence:

Thippeswamy H. Sannasiddappa th526@cam.ac.uk

Simon R. Clarke

s.r.clarke@reading.ac.uk

${ }^{\dagger}$ Present address:

Thippeswamy H. Sannasiddappa, Bacterial Infection Group, Department

of Veterinary Medicine, University of Cambridge, Cambridge, United Kingdom

Specialty section: This article was submitted to Antimicrobials, Resistance and Chemotherapy,

a section of the journal

Frontiers in Microbiology

Received: 22 June 2017 Accepted: 03 August 2017

Published: 23 August 2017

Citation:

Sannasiddappa TH, Lund PA and Clarke SR (2017) In Vitro Antibacterial

Activity of Unconjugated and Conjugated Bile Salts on

Staphylococcus aureus.

Front. Microbiol. 8:1581.

doi: 10.3389/fmicb.2017.01581
Bile salts are potent antimicrobial agents and are an important component of innate defenses in the intestine, giving protection against invasive organisms. They play an important role in determining microbial ecology of the intestine and alterations in their levels can lead to increased colonization by pathogens. We have previously demonstrated survival of the opportunistic pathogen Staphylococcus aureus in the human colonic model. Thus investigating the interaction between $S$. aureus and bile salts is an important factor in understanding its ability to colonize in the host intestine. Harnessing bile salts may also give a new avenue to explore in the development of therapeutic strategies to control drug resistant bacteria. Despite this importance, the antibacterial activity of bile salts on S. aureus is poorly understood. In this study, we investigated the antibacterial effects of the major unconjugated and conjugated bile salts on S. aureus. Several concentration-dependent antibacterial mechanisms were found. Unconjugated bile salts at their minimum inhibitory concentration (cholic and deoxycholic acid at 20 and $1 \mathrm{mM}$, respectively) killed $S$. aureus, and this was associated with increased membrane disruption and leakage of cellular contents. Unconjugated bile salts (cholic and deoxycholic acid at 8 and $0.4 \mathrm{mM}$, respectively) and conjugated bile salts (glycocholic and taurocholic acid at $20 \mathrm{mM}$ ) at their sub inhibitory concentrations were still able to inhibit growth through disruption of the proton motive force and increased membrane permeability. We also demonstrated that unconjugated bile salts possess more potent antibacterial action on $S$. aureus than conjugated bile salts.

\section{Keywords: viability, intracellular $\mathrm{pH}$, membrane permeability, bile salts, antibacterial}

\section{INTRODUCTION}

The human intestine is a complex ecosystem composed of commensal microflora species, various types of secretory fluids, fermentation metabolites of digested food, and host defense molecules (Sekirov and Finlay, 2009). A broad range of innate defenses in the intestine include acidic $\mathrm{pH}$, fermentation metabolites like short chain fatty acids (SCFA), high osmolarity, local gut mucosal immunity, colonization resistance by normal commensal bacteria, and bile salts. Despite these properties, the intestine is host to a complex microflora (Quigley, 2013; Zhang et al., 2015). While many of these microorganisms live as harmless commensals, there are also opportunist pathogens

Abbreviations: CA, cholic acid; CMC, critical micelle concentration; DCA, deoxycholic acid; GCA, glycocholic acid; TCA, taurocholic acid. 
(Baumler and Sperandio, 2016). Survival and subsequent colonization by opportunist pathogens of the human intestinal tract requires them to resist these innate defenses. Thus study of innate antimicrobials may lead to development of novel control strategies against pathogens.

Staphylococcus aureus is a highly adaptable human opportunistic pathogen responsible for many infections and deaths worldwide (Kluytmans and Wertheim, 2005; Tong et al., 2015). The bacterium lives as a commensal in the nares of $20-25 \%$ of the population at any one time (Peacock et al., 2001; Wertheim et al., 2004). While nasal colonization is a well-established risk factor for most types of $S$. aureus infections, several studies have suggested that intestinal colonization, which occurs in $20 \%$ of individuals, could have important clinical implications (Acton et al., 2009). Patients with $S$. aureus intestinal colonization can serve as an important source of transmission as they often contaminate the adjacent environment (Masaki et al., 2003; Kernbauer et al., 2015) and also display an increased frequency of skin colonization (Bhalla et al., 2007; Lindberg et al., 2011). A study in an intensive care unit showed that patients with both rectal and nares colonization by $S$. aureus had a higher risk of disease than did patients with nasal colonization alone (Squier et al., 2002; Faden et al., 2010).

The ability of $S$. aureus to survive in the intestine is an important aspect of its capacity to transmit from host to host. In particular, bile salts in the intestine are important innate defense molecules and potent antibacterial agents (Sung et al., 1993; Itoh et al., 1999; Begley et al., 2005). This may have been part of the basis for the success of a 1000-year-old Anglo-Saxon remedy used to treat microbial eye infections, which contains bile salts and was effective against $S$. aureus infections in chronic mouse wound models (Harrison et al., 2015). Patients with cirrhosis show increased bacterial overgrowth due to decreased levels of intraluminal bile salts in the small intestine (Chang et al., 1998; Bauer et al., 2001) and oral treatment with bile salts in cirrhotic rats resulted in reduced small intestinal bacterial overgrowth (Lorenzo-Zuniga et al., 2003). Thus bile salts serve not only as digestive molecules aiding in lipid digestion, but also as potent antibacterial agents in the intestines (Begley et al., 2005).

Thus the interaction between $S$. aureus and human bile salts is an important factor in its ability to colonize in the host intestine particularly in the colon. Despite this importance, the mode of action of these bile salts on $S$. aureus is still not fully understood. The amphipathic nature and presence of a steroid nucleus in their structure makes human bile salts potent antibacterial agents mainly due to their membrane damaging effects (Scholmerich et al., 1984). Bile salts also inhibit bioenergetic process by intracellular acidification, dissipation of the proton motive force, and induction of DNA damage and protein denaturation (Prieto et al., 2004; Kurdi et al., 2006; Merritt and Donaldson, 2009). In this study, we aimed to determine the mechanism of antibacterial action of major human bile salts on $S$. aureus. This revealed multiple mechanisms of killing of $S$. aureus by the ability of bile salts to disrupt essential membrane functions and bioenergetic processes.

\section{MATERIALS AND METHODS}

\section{Bacteria and Growth Conditions}

Staphylococcus aureus SH1000 (Horsburgh et al., 2002) was grown on Brain Heart Infusion (BHI) (Oxoid) broth or agar at $37^{\circ} \mathrm{C}$. All experiments were performed at $\mathrm{pH} 7$ in growth media or buffer as indicated in experimental methods.

\section{Determination of MIC}

Bile salts were purchased from Sigma-Aldrich, United Kingdom. Minimum inhibitory concentrations (MICs) were determined by the broth dilution method as described previously (Sannasiddappa et al., 2015). Briefly, two fold dilutions of bile salts in BHI broth were inoculated with S. aureus SH1000 at cell density of $10^{6} \mathrm{CFU} / \mathrm{ml}$. Broth dilution tubes with no visible growth after $16 \mathrm{~h}$ incubation at $37^{\circ} \mathrm{C}$ were read as MIC value. The MIC range determined by two fold serial dilution was further narrowed down to determine appropriate MICs.

\section{Time-Course Measurement of Bacterial Viability upon Exposure to Bile Salts}

Bacterial viability upon exposure to bile salts at different time periods was determined as previously described (Sannasiddappa et al., 2015). Briefly, overnight grown S. aureus SH1000 were cultured until mid-exponential phase in fresh $\mathrm{BHI}$ broth at $37^{\circ} \mathrm{C}$ shaking incubator under aerobic conditions. After harvesting, the cells were washed twice in sterile 5 mM HEPES buffer ( $\mathrm{pH} 7.2)$ with $10 \mathrm{mM}$ glucose and resuspended in the same buffer to an $\mathrm{OD}_{600}$ of 0.5 . Portions of this cell suspension were incubated with various concentrations of CA, DCA, GCA, and TCA for $30 \mathrm{~min}$ at $37^{\circ} \mathrm{C}$. At 10 -min intervals until $30 \mathrm{~min}$, cell suspension dilutions, from each of the bile salt treated groups, were made with sterile peptone saline diluent. Cells from appropriate dilutions were plated onto tryptic soy agar plates, and incubated overnight at $37^{\circ} \mathrm{C}$. Colonies were counted and the $\log _{10} \mathrm{CFU} / \mathrm{ml}$ viabilities were calculated based on the counts from initial untreated (control) cell suspension.

\section{Intracellular pH Measurement upon Exposure to Bile Salts}

The internal pH of the S. aureus SH1000 cells upon exposure to various concentrations of the selected bile salts over a time-course were measured according to the method described previously (Breeuwer et al., 1996) except that the experiments were performed in $50 \mathrm{mM}$ potassium phosphate buffer with $\mathrm{pH} 7$ and $10^{7} \mathrm{CFU} / \mathrm{ml}$ cells were preloaded with $3.4 \mu \mathrm{M}$ of membrane permeable $\mathrm{pH}$ sensitive precursor probe 5 (and 6-)-carboxyfluorescein diacetate succinimidyl ester for $15 \mathrm{~min}$ at $37^{\circ} \mathrm{C}$.

\section{Measurement of the Transmembrane Electrical Potential}

Changes in the membrane potentials of the S. aureus SH1000 upon energization and addition of various concentrations of selected bile salts were monitored using cationic membrane potential sensitive cyanine fluorescent dye $\mathrm{DiSC}_{3}(5)$, as described 
TABLE 1 | Minimum inhibitory concentration (MIC) of bile salts for $S$. aureus SH1000.

\begin{tabular}{lc}
\hline Bile salt & MIC (mM) \\
\hline CA & 20 \\
DCA & 1 \\
GCA & $>200$ \\
TCA & $>200$
\end{tabular}

CA, cholic acid; DCA, deoxycholic acid; GCA, glycocholic acid; TCA, taurocholic acid.

previously (Cheng et al., 2009) except that experiments were performed in $5 \mathrm{mM}$ HEPES buffer at $\mathrm{pH} 7$ and the cells were loaded with $1 \mu \mathrm{M} \mathrm{DiSC}_{3}$ (5). Membrane potential measurements were compared with $4 \mu \mathrm{M}$ valinomycin positive control.

\section{Determination of Intracellular Potassium Levels}

The intracellular pool of potassium upon treatment with various concentrations of selected bile salts was quantified by atomic absorption spectroscopy as described previously (Ioannou et al., 2007) except that experiments were performed in $5 \mathrm{mM}$ HEPES buffer $(\mathrm{pH} 7)$ at a cell density of $10^{8} \mathrm{CFU} / \mathrm{ml}$. Samples from each of the test (bile salts) and control groups ( $4 \mu \mathrm{M}$ valinomycin and $100 \mu \mathrm{g} / \mathrm{ml}$ lysostaphin) were collected over a time-course of $20 \mathrm{~min}$ and filtered using a $0.22 \mu \mathrm{m}$ pore size membrane filter. The potassium ion concentration in the filtrate samples was determined using a PerkinElmer 1100B atomic absorption spectrophotometer in flame emission mode.

\section{Leakage of Cellular 260 and $280 \mathrm{~nm}$ Absorbing Material}

Leakage of nucleic acids $(260 \mathrm{~nm})$ and proteins $(280 \mathrm{~nm})$ upon treatment with the bile salts along with positive control (cells treated with $100 \mu \mathrm{g} / \mathrm{ml}$ lysostaphin) were monitored by measuring 260 and $280 \mathrm{~nm}$ absorbance in a Bio-Tek Epoch microplate spectrophotometer in UV-Visible mode. Bacterial cells were cultured and treated with selected bile salts, and samples were collected in the same manner as in the case of determination of intracellular potassium leakage except that the filtrate samples were collected over a time course of 30, 60, 90, and $120 \mathrm{~min}$.

\section{Determination of Membrane Integrity}

Changes in the membrane integrity of S. aureus SH1000 cells treated with various bile salts were assessed by fluorescence based confocal microscopy of dead cells with compromised cell membranes, to determine the proportion of the cells with

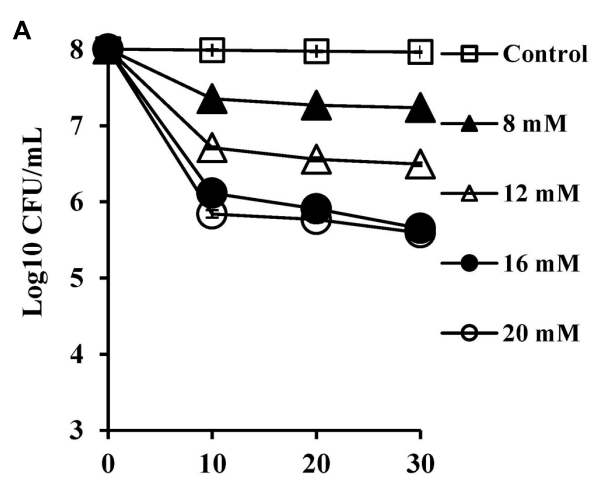

Time (minutes)

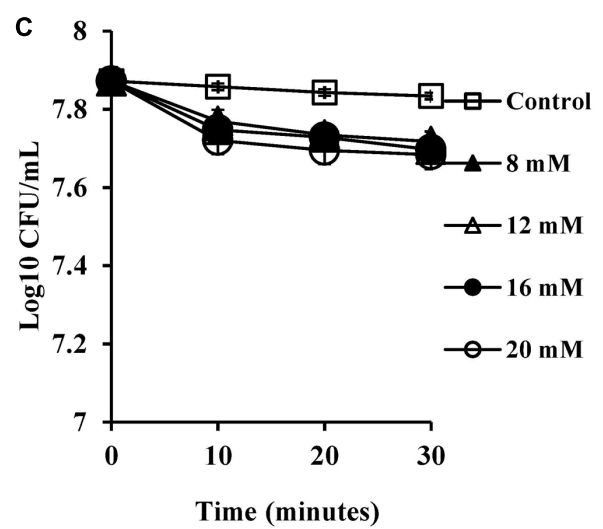

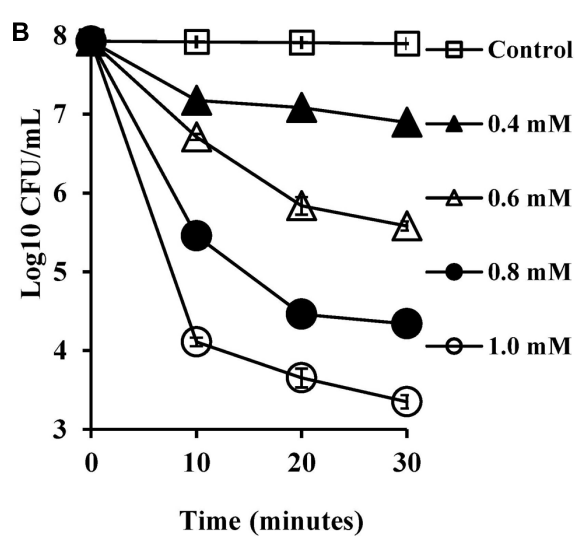

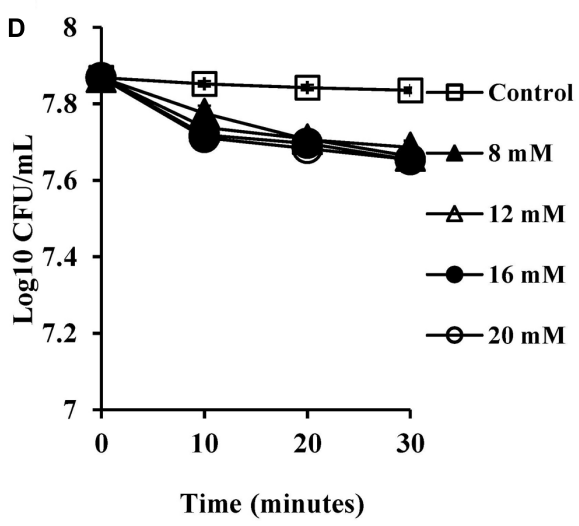

FIGURE 1 | Effect of bile salts on viability of S. aureus SH1000. Experiments were performed at a cell density of $10^{8} \mathrm{CFU} / \mathrm{ml}$ following exposure to (A) CA, (B) DCA, (C) GCA, and (D) TCA. Data represents mean \pm standard error of mean from three independent experiments. 
intact cell membranes. After the treatment with bile salts, cells were subsequently incubated with a fluorescent dye mixture (component A and component B) of the LIVE/DEAD BacLight bacterial viability kit (Molecular Probes, Invitrogen) according to manufacturer's instructions for $30 \mathrm{~min}$ at $37^{\circ} \mathrm{C}$. Images were acquired in confocal laser scanning microscope (Leica TCS SP2, Leica Microsystems, United Kingdom) and analysis was performed using the Image J analysis system.

\section{Scanning Electron Microscopy of}

\section{S. aureus Treated with Various Bile Salts}

Staphylococcus aureus SH1000 cells grown to mid-exponential phase were harvested and washed twice with $5 \mathrm{mM}$ HEPES buffer ( $\mathrm{pH} 7$ ). Washed cells were resuspended at $10^{8} \mathrm{CFU} / \mathrm{ml}$ in the same buffer with or without various bile salts and incubated at $37^{\circ} \mathrm{C}$ for $30 \mathrm{~min}$. After incubation, cells were centrifuged and pellets were fixed overnight with $2 \%$ paraformaldehyde, $2.5 \%$ glutaraldehyde fixative in $5 \mathrm{mM}$ HEPES buffer at $4^{\circ} \mathrm{C}$. Cell pellets were dehydrated through a graded acetone series at room temperature, critical-point dried by the $\mathrm{CO}_{2}$ method, and coated with gold in a sputter coater. Cells were examined and photographed with an FEI Quanta scanning electron microscope operating at $20 \mathrm{kV}$.

\section{Transmission Electron Microscopy of}

\section{S. aureus Treated with Various Bile Salts}

Staphylococcus aureus SH1000 cells for transmission electron microscopy experiments were prepared similar to that of scanning electron microscopy with following differences. After primary fixation with the $2 \%$ paraformaldehyde, $2.5 \%$ glutaraldehyde fixative in $5 \mathrm{mM}$ HEPES buffer, the cells were post fixed with $1 \%$ osmium tetroxide for $1 \mathrm{~h}$ and dehydrated through a graded acetone series. Cells were then embedded into resin at $60^{\circ} \mathrm{C}$ for $48 \mathrm{~h}$. After embedding, cells were sectioned into 70-80 nm thickness using an ultramicrotome (Reichert-Jung Ultracut) and mounted on formvar/carbon 200 mesh copper grids (Agar Scientific), doubly stained with $2 \%$ uranyl acetate and $0.4 \%$ lead citrate. The stained cells were viewed under a
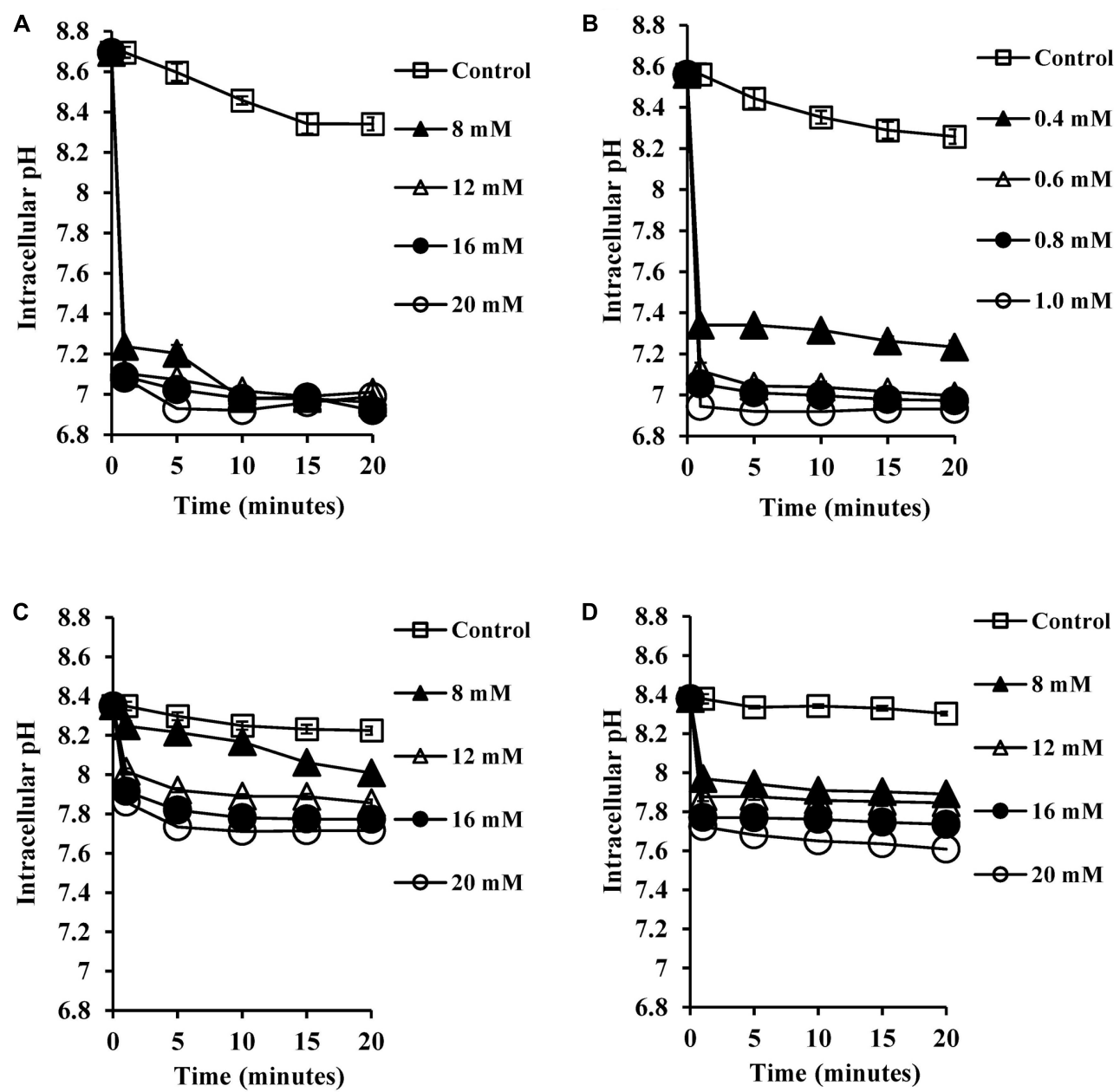

FIGURE 2 | Effect of bile salts on intracellular pH of S. aureus SH1000. Experiments were performed at a density of $10^{7} \mathrm{CFU} / \mathrm{ml}$ cells preloaded with fluorescent probe (cFSE) and energized with $10 \mathrm{mM}$ glucose following exposure to (A) CA, (B) DCA, (C) GCA, and (D) TCA. Nigericin at $4 \mu \mathrm{M}$ was added to check the dissipation of intracellular $\mathrm{pH}$. Data represents mean \pm standard error of mean from three independent experiments. 
Philips CM 20 transmission electron microscope operating at $200 \mathrm{kV}$.

\section{Statistical Analysis}

All experiments were repeated three times and data were presented as mean \pm standard error of mean unless otherwise mentioned. Analysis was done in GraphPad Prism 5 software. Experimental data of membrane integrity and scanning electron microscopy measurements were analyzed by one-way ANOVA method and rest of the experimental data were analyzed by two-way ANOVA method, using Bonferroni post-test analysis. $P$-value $<0.05$ was considered as statistically significant unless otherwise mentioned.

\section{RESULTS}

\section{Minimum Inhibitory Concentration}

The MIC of bile salts used in this study are summarized in Table 1. As shown in Table 1, DCA showed 20 times more potent antibacterial activity than CA. CA showed at least 10 times more antibacterial activity when compared to its conjugated forms, GCA and TCA. The MIC of GCA and TCA were found to be $>200 \mathrm{mM}$.

\section{Time-Course Bacterial Viability Kinetics}

The viability of $S$. aureus SH1000 cells upon exposure to bile salts used in this study were determined by a viable plate count method with the limit of detection at $3 \log _{10} \mathrm{CFU} / \mathrm{ml}$. A dose-dependent reduction in viability was noticed over $30 \mathrm{~min}$ exposure. Almost $1 \log _{10} \mathrm{CFU} / \mathrm{ml}$ reduction $(P<0.01)$ at $8 \mathrm{mM}$, and $1.5-2$ $\log _{10} \mathrm{CFU} / \mathrm{ml}$ reduction in viability $(P<0.001)$ at 16 and $20 \mathrm{mM}$ was found for CA (Figure 1A). DCA showed a similar pattern of dose-dependent reduction kinetics of viability (Figure 1B), but was effective at much lower concentrations. Even $0.4 \mathrm{mM}$ resulted in a statistically significant reduction in viability over $30 \min (P<0.01)$. The conjugated bile salts, GCA and TCA (Figures 1C,D) were tested only at sub-MICs and also exhibited some dose-dependent reduction in viability. However, only a
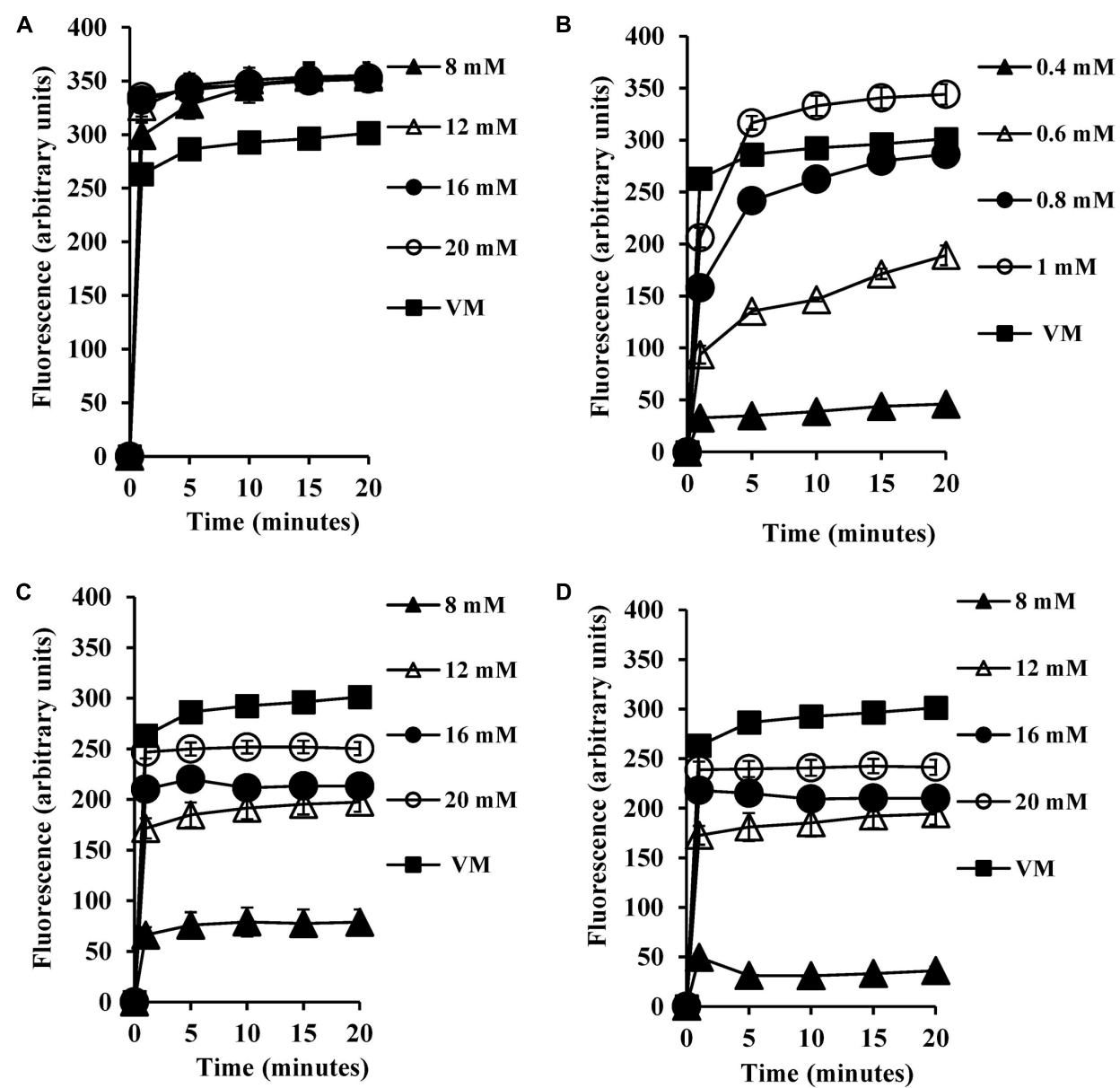

FIGURE 3 | Effect of bile salts on the transmembrane electrical potential of $\mathrm{S}$. aureus SH1000. Experiments were performed at a density of $10^{7} \mathrm{CFU} / \mathrm{ml}$ cells preloaded with the $\mathrm{DiSC}_{3}$ (5) dye and energized with $10 \mathrm{mM}$ glucose following exposure to (A) CA, (B) DCA, (C) GCA, and (D) TCA. Dissipation of transmembrane electric potential was measured as the increase in the $\mathrm{DiSC}_{3}(5)$ fluorescence. $\mathrm{VM}$, valinomycin at $4 \mu \mathrm{M}$ was used as a positive control to check the dissipation of transmembrane electric potential. Data represents mean \pm standard error of mean from three independent experiments. 
$0.2 \log _{10} \mathrm{CFU} / \mathrm{ml}$ reduction in viability $(P<0.01)$ was found at the highest concentration $(20 \mathrm{mM})$ tested. The order of potency in terms of kill kinetics was thus DCA $>$ CA $>$ GCA $=$ TCA.

\section{Bile Salts Reduce Intracellular pH}

SCFA, being weak acids (pKa of 4.8-5.2; Salmond et al., 1984; Russell, 1991), will exist partially in their protonated forms at $\mathrm{pH} 5.5$ in the human colon. These hydrophobic molecules can traverse the plasma membrane, become deprotonated in the higher $\mathrm{pH}$ environment of the cytoplasm and reduce the intracellular pH (Salmond et al., 1984; Russell, 1991). Therefore, we expected that CA and DCA which are also weak acids would have similar effects in reducing intracellular $\mathrm{pH}$. The intracellular $\mathrm{pH}$ of energized cells was monitored over a period of $20 \mathrm{~min}$ exposure to bile salts. The reduction in $\mathrm{pH}$ was found to be complete, which was confirmed by the addition of nigericin (a known ionophore which dissipates internal $\mathrm{pH}$ ), which caused no further reduction of the internal $\mathrm{pH}$ of the cells. CA and
DCA were found to reduce internal $\mathrm{pH}$ (Figures 2A,B) even at sub-inhibitory concentrations of 8 and $0.4 \mathrm{mM}$, respectively $(P<0.001)$. At the MIC, unconjugated bile salts caused complete reductions of the internal $\mathrm{pH}$ to the external $\mathrm{pH}(P<0.001)$. Concentrations which resulted in complete dissipation of internal $\mathrm{pH}$ and reduction in the viability correlated closely with MICs of CA and DCA. Conjugated bile salts, GCA and TCA were also found to have a small effect on internal $\mathrm{pH}$ (Figures 2C,D) at $8 \mathrm{mM}(P<0.01)$. However, they were found to be significantly less effective when compared to the unconjugated bile salts. This is likely be to because conjugation makes them strong acids that are completely ionized at a neutral $\mathrm{pH}$, resulting in an inability to cross cell membranes (Kurdi et al., 2006).

\section{Bile Salts Dissipate Transmembrane Electrical Potential}

Most microorganisms derive their energy from proton motive force consisting of a combination of an electrical potential and
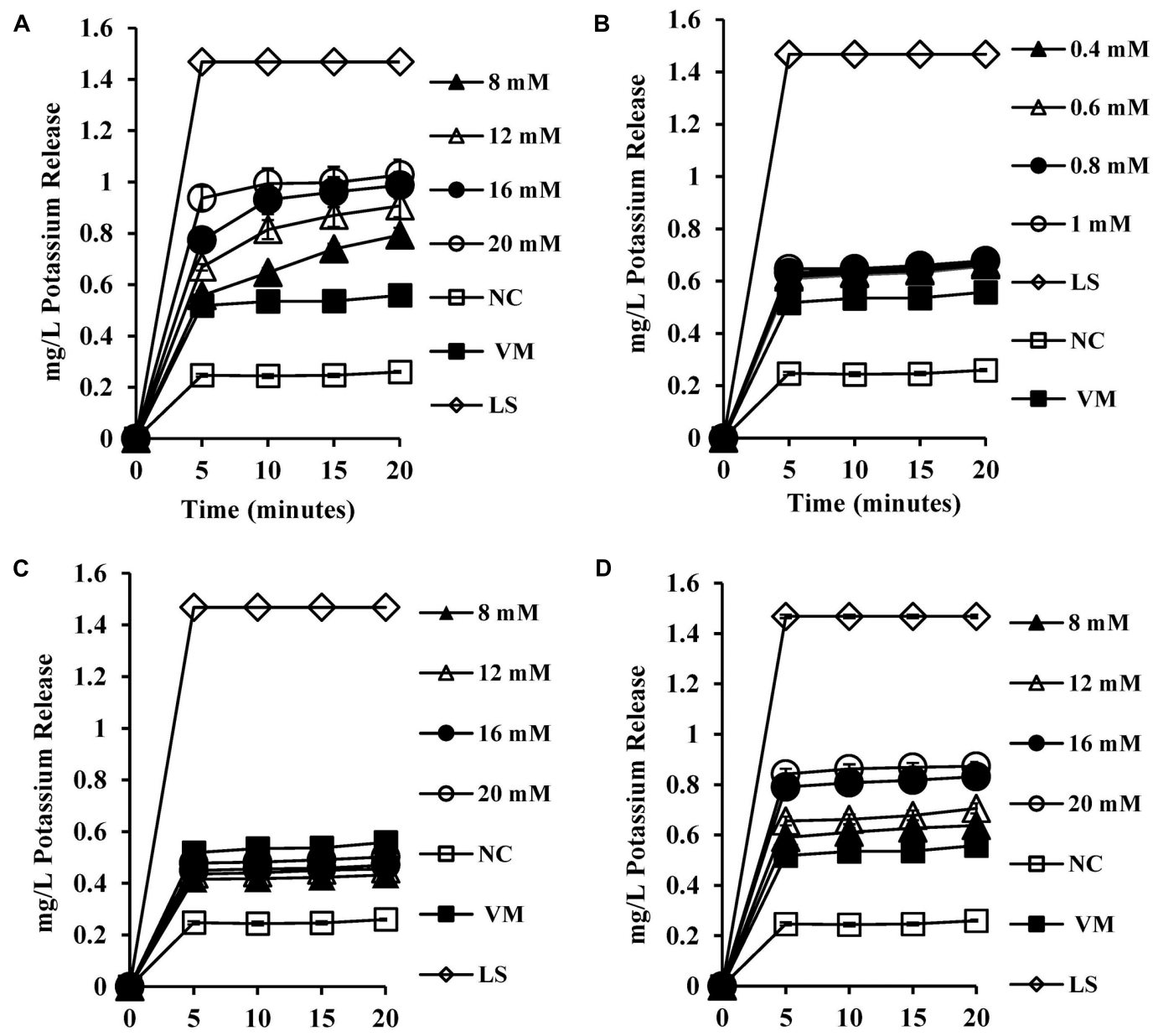

D

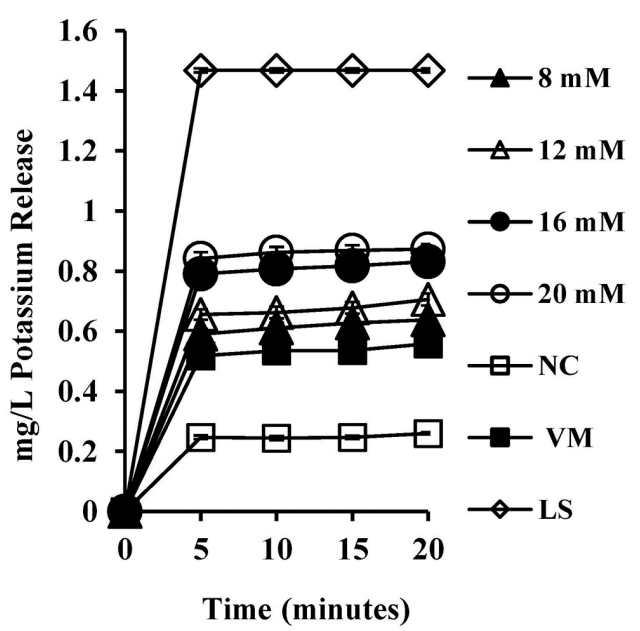

FIGURE 4 | Effect of bile salts on intracellular leakage of potassium from S. aureus SH1000. Experiments were performed at a cell density of $10^{8} \mathrm{CFU} / \mathrm{ml}$ following exposure to (A) CA, (B) DCA, (C) GCA, and (D) TCA. NC, negative control (untreated cells); VM, valinomycin at $4 \mu \mathrm{M}$; LS, cells treated with $100 \mu \mathrm{g} / \mathrm{ml}$ lysostaphin for $30 \mathrm{~min}$. Data represents mean \pm standard error of mean from three independent experiments. 


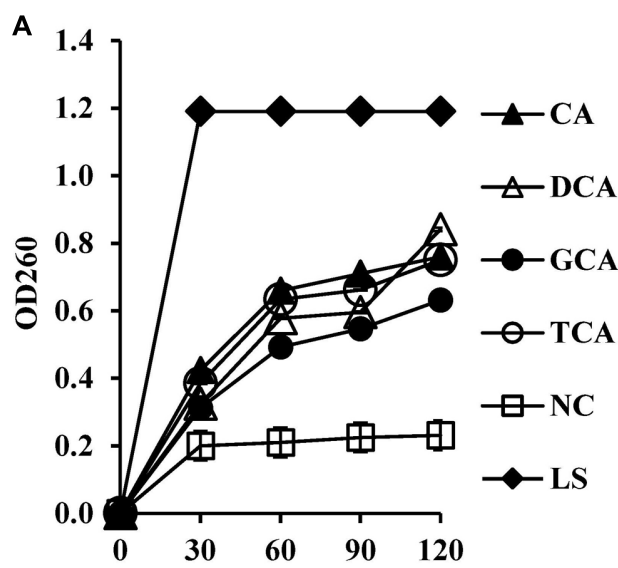

Time (minutes)

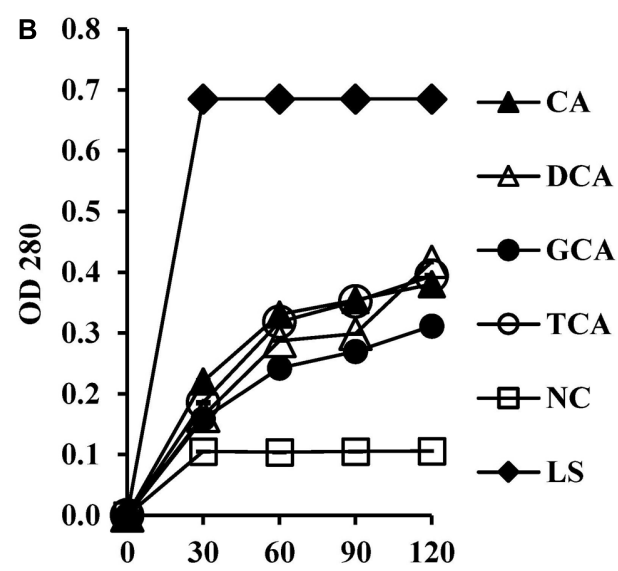

Time (minutes)

FIGURE 5 | Measurement of cellular leakage of nucleic salts (A) and protein (B) from S. aureus SH1000 upon exposure to bile salts. Experiments were performed at a cell density of $10^{8} \mathrm{CFU} / \mathrm{ml}$ following exposure to $20 \mathrm{mM} \mathrm{CA}, 1 \mathrm{mM}$ DCA, $20 \mathrm{mM}$ GCA, and $20 \mathrm{mM}$ TCA. NC, negative control (untreated cells); LS, cells treated with $100 \mu \mathrm{g} / \mathrm{ml}$ lysostaphin. Data represents mean \pm standard error of mean from three independent experiments.

chemical proton gradient. We predicted that the decrease in the intracellular $\mathrm{pH}$ seen upon exposure to bile salts would therefore lead to alterations in the membrane potential. We therefore measured the transmembrane electrical potential using the membrane potential sensitive dye $\mathrm{DiSC}_{3}$ (5). The fluorescent probe $\mathrm{DiSC}_{3}$ (5) distributes between cells and medium depending on the cytoplasmic membrane potential. Once inside cells, it becomes concentrated and self-quenches its fluorescence. If bile salts cause cytoplasmic membrane disruption or reduce the $\mathrm{pH}$ gradient across the membrane, the membrane potential will be dissipated resulting in an increase in $\mathrm{DiSC}_{3}$ (5) fluorescence. As shown in Figure $\mathbf{3 A}, \mathrm{CA}$ at $8 \mathrm{mM}$ did indeed dissipate the membrane potential, and at $20 \mathrm{mM}$ dissipation was well above that seen with the $4 \mu \mathrm{M}$ valinomycin positive control $(P<0.001)$. The DCA dissipated membrane potential at $0.6 \mathrm{mM}$ (Figure 3B) and at $1 \mathrm{mM}$ dissipation was well above the $4 \mu \mathrm{M}$ valinomycin positive control $(P<0.001)$. The conjugated bile salts, GCA and TCA dissipated membrane potential at $12 \mathrm{mM}$ (Figures 3C,D; $P<0.01$ ). However, these conjugated bile salts at $20 \mathrm{mM}$ were unable to dissipate membrane potential completely when compared to the $4 \mu \mathrm{M}$ valinomycin positive control, as expected given their limited effects on internal $\mathrm{pH}$ (Begley et al., 2005).

\section{Intracellular Potassium Levels}

To test the permeability of intracellular ions caused by bile salt mediated membrane damage, we measured the amount of intracellular potassium released into HEPES buffer upon exposure to bile salts. CA exposure at $8 \mathrm{mM}$ and above (Figure 4A) resulted in significant dose-dependent release of intracellular potassium $(P<0.001)$ when compared to both the negative control and valinomycin positive control. All the concentrations tested for DCA (Figure 4B) exhibited single splash type pattern of intracellular release of potassium
TABLE 2 | Monitoring of membrane integrity of S. aureus SH1000 cells treated with bile salts.

\begin{tabular}{lrr}
\hline Bile salt & Integrity (\%) & \multicolumn{1}{c}{ Viability (\%) } \\
\hline Control & $91.02 \pm 1.04$ & $91.60 \pm 1.05$ \\
CA & $2.95 \pm 0.92$ & $2.35 \pm 0.93$ \\
DCA & $1.58 \pm 0.53$ & $0.97 \pm 0.53$ \\
GCA & $49.36 \pm 1.49$ & $49.38 \pm 1.51$ \\
TCA & $51.08 \pm 1.95$ & $51.12 \pm 1.97$
\end{tabular}

Bacterial cells were treated at MIC of CA and DCA, and sub-MIC (20 mM) of GCA and TCA at a cell density of $10^{8} \mathrm{CFU} / \mathrm{ml}$ for $30 \mathrm{~min}$. Data represents mean \pm standard error of mean from three independent experiments. Number of cells counted $=1600$. CA, cholic acid; DCA, deoxycholic acid; GCA, glycocholic acid; TCA, taurocholic acid.

and were statistically significant when compared to negative control $(P<0.01)$. The conjugated bile salts GCA and TCA also exhibited a dose-dependent intracellular potassium release pattern (Figures 4C,D) and release of potassium at $8 \mathrm{mM}$ and above was statistically significant $(P<0.001)$ when compared to negative control. The release of potassium at $20 \mathrm{mM}$ GCA was not significant when compared to $4 \mu \mathrm{M}$ valinomycin control. However, TCA at $20 \mathrm{mM}$ showed statistically significant release of potassium when compared to $4 \mu \mathrm{M}$ valinomycin control $(P<0.01)$.

\section{Leakage of Cellular 260 and $280 \mathrm{~nm}$ Absorbing Material}

To test whether membrane damage mediated by bile salts resulted in leakage of intracellular macromolecules such as nucleic acids and proteins, UV absorbance values were measured at 260 and $280 \mathrm{~nm}$ following exposure of cells to bile salts. UV absorbance values at 260 and $280 \mathrm{~nm}$ increased significantly (Figures 5A,B) when compared to the negative control $(P<0.01)$. UV absorbance values increased with exposure time. 


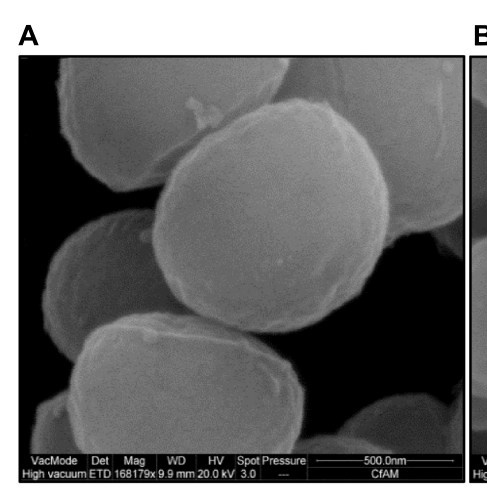

D
B

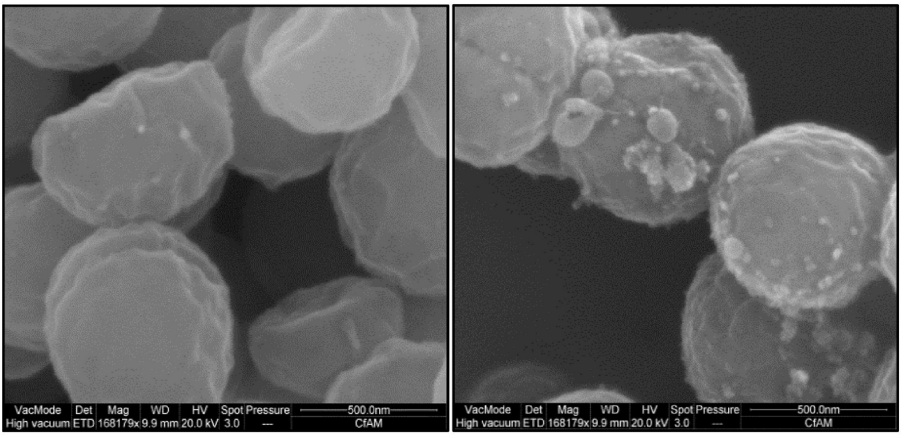

$\mathrm{E}$

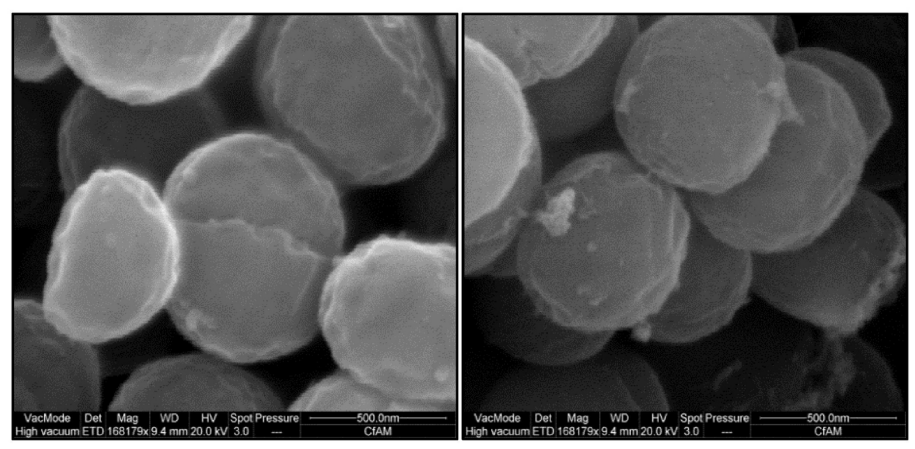

FIGURE 6 | Surface morphology of $S$. aureus $\mathrm{SH} 1000$ in the presence of bile salts. Scanning electron microscopy was used to investigate the surface morphology of (A) cells untreated or treated with (B) 20 mM CA, (C) 1 mM DCA, (D) 20 mM GCA, and (E) 20 mM TCA at a density of $10^{8}$ CFU/ml for 30 min. Bar = 500 nm.

\section{Membrane Integrity}

The membrane integrity and viability of S. aureus SH1000 cells upon exposure to bile salts was investigated by a fluorescent dye based confocal laser scanning electron microscopy. Image analysis revealed green fluorescence in cells with intact membrane and red fluorescence in cells with damaged membrane (Supplementary Figure 1). The unconjugated bile salts (CA and DCA) treated cells showed nearly $97 \%$ reduction in the membrane integrity $(P<0.001)$ and $97 \%$ reduction in the viability at 20 and $1 \mathrm{mM}$, respectively after $30 \mathrm{~min}$ exposure (Table 2), whereas GCA and TCA treated cells showed 50\% reduction in membrane integrity and 50\% reduction in the viability at $20 \mathrm{mM}(P<0.001)$ when compared to untreated cells (Table 2).

\section{Surface Morphology of S. aureus Treated with Bile Salts}

Scanning electron microscopy demonstrated altered surface morphology upon exposure to unconjugated bile salts (CA and DCA) at their MIC, and conjugated bile salts (GCA and TCA) at sub-MIC of $20 \mathrm{mM}$. Untreated cells had a well-defined intact spherical shape with a smooth surface morphology (Figure 6A). Morphological defects were severe for cells exposed to CA and DCA when compared to GCA and TCA. The cells exposed to CA and DCA had shrunken appearance and indented on the surfaces indicating possible leakage of intracellular contents. Vesicles and blebs were also present on the surface (Figures 6B,C). Cells exposed to GCA and TCA also had a shrunken appearance with dents on the surface (Figures 6D,E).

\section{Ultra-Structural Morphology of S. aureus Treated with Bile Salts}

Transmission electron microscopy demonstrated pronounced ultra-structural defects in bile salts treated cells when compared untreated cells. The untreated cells revealed intact and well defined cell membrane, cell wall and midline septum with homogenous cytoplasm (Figure 7A). Cell wall breaks, thinning and disintegration of cell wall, cell membrane breaks, and abnormal septation were noticed in the cells exposed to all four bile salts studied (Figures 7B-E). Cells exposed to CA and DCA had membrane enclosed and non-membrane enclosed mesosome like structures inside the cytoplasm (Supplementary Figure 2) reflecting possible cell membrane damage and increased permeability. Many ghost cells (cells with empty cytoplasm) were also found in CA, DCA, and TCA treated cells. Cell lysis was more pronounced in CA and DCA treated cells.

\section{DISCUSSION}

Human bile salts in the intestine are an important facet of innate defense against enteric pathogens. They play an important role in maintaining indigenous microbiota and protection against enteric pathogens in the intestine (Sung et al., 1993; Itoh et al., 1999; Begley et al., 2005). Reduced levels of 

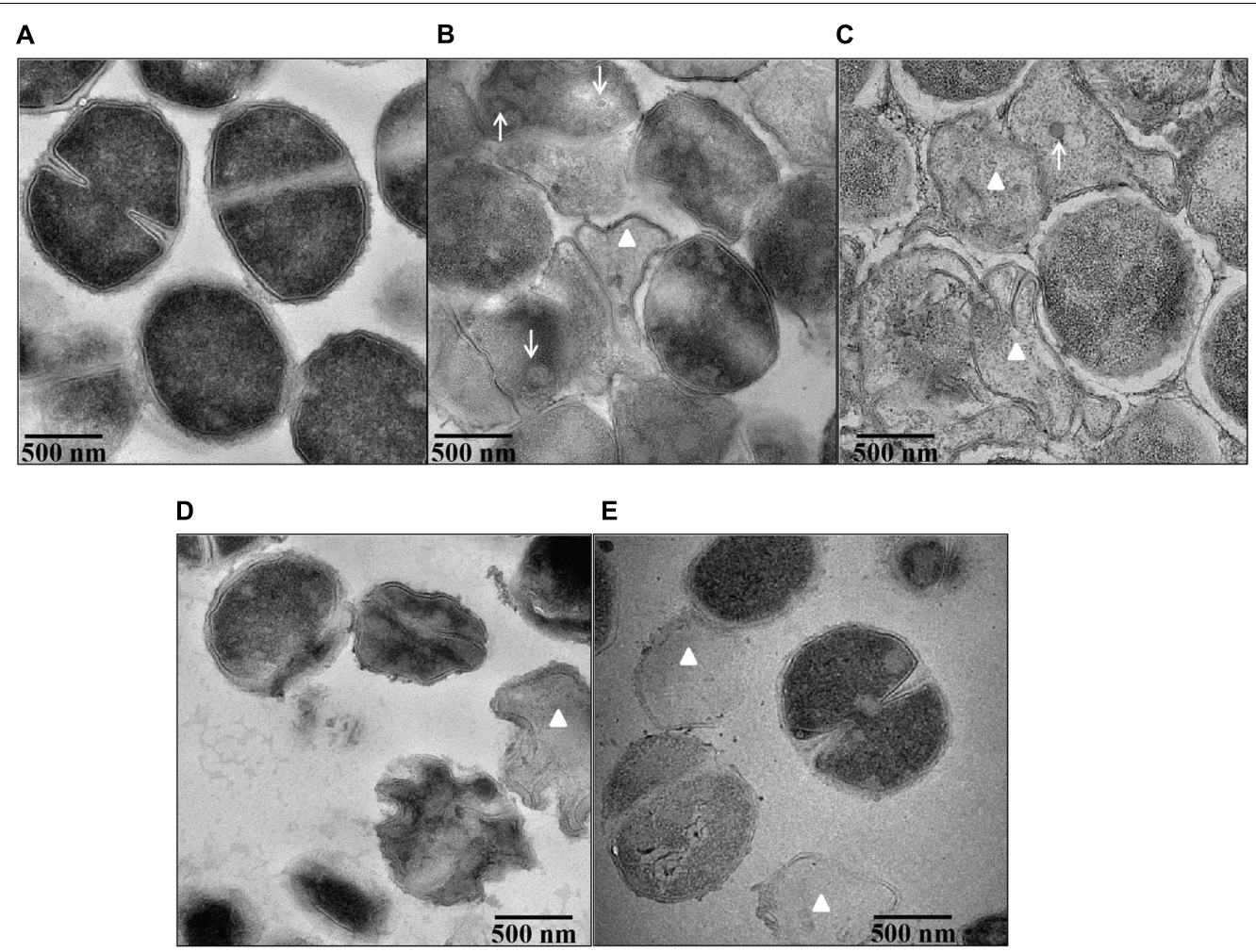

FIGURE 7 | Ultra structural morphology of S. aureus SH1000 in the presence of bile salts. Transmission electron microscopy was used to investigate the interior morphological details of (A) cells untreated or treated with (B) 20 mM CA, (C) 1 mM DCA, (D) 20 mM GCA, and (E) 20 mM TCA at a density of $10^{8}$ CFU/ml for $30 \mathrm{~min}$. Bar $=500 \mathrm{~nm}$. White arrows represent mesosome like structures. White triangles represent ghost cells.

bile salts in the intestine correlate with cases of bacterial overgrowth and translocation in the small intestine, resulting in endotoxemia in cirrhotic rats (Lorenzo-Zuniga et al., 2003). Oral supplementation with bile salts in such rats can prevent small intestinal bacterial overgrowth and translocation (LorenzoZuniga et al., 2003).

If one is to develop bile salts or related molecules as potential antibacterial therapy against pathogens, their mode of action needs to be established. Up till now, knowledge on bactericidal action of bile salts on $S$. aureus has been limited. Here, we propose that bile salts can kill $S$. aureus in several ways which depend on their concentration and physicochemical properties.

The accumulation of weak organic acids in the cytoplasm involves passive diffusion of the protonated form of weak acid across membranes, followed by its intracellular deprotonation and decrease in intracellular pH (Salmond et al., 1984; Russell, 1991). Bile salts, due to their structural and chemical properties, are generally considered to be weak acids and were shown to decrease intracellular $\mathrm{pH}$ and dissipate transmembrane potential in lactobacilli and bifidobacteria (Kurdi et al., 2006). In this study, a dose-dependent decrease in the intracellular $\mathrm{pH}$ in the presence of bile salts was observed. The decrease of intracellular $\mathrm{pH}$ was more marked with unconjugated bile salts (CA and DCA) compared to conjugated bile salts (GCA and TCA). This difference could be attributed to the higher $\mathrm{pKa}$ values of unconjugated bile salts (6.4 and 6.58 for CA and DCA, respectively) compared to conjugated bile salts (4 and 2 for GCA and TCA, respectively), meaning they are less dissociated at $\mathrm{pH} 7$ and hence more able to cross the hydrophobic cell membrane (Carey, 1984; Cantafora et al., 1987). Conjugated bile salts are stronger acids having lower pKa values (Carey, 1984), and at physiological pH 7 are effectively fully ionized, unable to cross cell membrane unless a specific transporter is available (Begley et al., 2005). However, data presented herein also demonstrate a significant decrease in the intracellular $\mathrm{pH}$ at a concentration of $8 \mathrm{mM}$ GCA or TCA. This concentration is close to the CMCs for GCA and TCA (7.1 and $11 \mathrm{mM}$, respectively) and it is thus possible that direct membrane damage is occurring in these cells exposed to $8 \mathrm{mM}$ GCA or TCA (Roda et al., 1983; Bhairi and Mohan, 2007). Many antibacterial agents act by disrupting the cytoplasmic membrane resulting in loss of proton gradients and electrical potential across the membrane leading eventually to cell death (Nelson et al., 2009). Our results also showed a dose-dependent decrease in the transmembrane electrical potential of bile salt treated cells. Concentrations required for the reduction of transmembrane electrical potential were below the CMC of unconjugated bile salts (12 and $3 \mathrm{mM}$ for CA and DCA, respectively) and above the CMC of conjugated bile salts. Thus reduction in the intracellular $\mathrm{pH}$ and transmembrane potential suggest that a dissipation of proton motive force is involved in bile salt mediated growth inhibition. 
Our data also showed a significant (20-fold) difference between the MICs of CA and DCA, and their effect on internal $\mathrm{pH}$ and transmembrane electrical potential, which cannot simply be attributed to a difference in their pKa values (Carey, 1984; Cantafora et al., 1987). The more hydrophobic DCA, with two $\mathrm{OH}$ groups, passively flip-flops through small unilamellar vesicles at least 10 times faster than $\mathrm{CA}$ with three $\mathrm{OH}$ groups (Kamp et al., 1993). The more rapid permeation of DCA through the membrane may explain the large difference in MIC and intracellular $\mathrm{pH}$ reduction concentrations between CA and DCA.

The reduction in the membrane integrity demonstrated by fluorescent dye staining of $S$. aureus treated with unconjugated bile salts at their MIC, and conjugated bile salts at sub MIC of $20 \mathrm{mM}$ suggested that membrane damage, which is associated with increased permeability, was occurring. This hypothesis was strengthened by detection of significant leakage of intracellular potassium from $S$. aureus cells following exposure to unconjugated and conjugated bile salts. Previous research demonstrated a similar alteration in the membrane integrity in lactobacilli and bifidobacteria, following exposure to unconjugated bile salts (Kurdi et al., 2006). Increased uptake of gentamicin in Lactobacillus plantarum (Elkins and Mullis, 2004) and rifaximin in enterotoxigenic E. coli (Darkoh et al., 2010) cells treated with bile salts suggests that besides ions, low molecularweight metabolites might also cross the cell membrane when bile salts are present at MIC. Our study also showed a significant increase in the leakage of macromolecules such as proteins and nucleic acids in the presence of unconjugated bile salts (at MIC) and conjugated bile salts (at $20 \mathrm{mM}$ ), suggesting substantial cell membrane damage occurred. Bile salts at higher concentrations rapidly dissolve membrane lipids and cause dissociation of membrane proteins. This rapid solubilization effect results in leakage of cellular contents and cell death (Noh and Gilliland, 1993). Subtle effects on membrane permeability and fluidity, including altered membrane bound enzyme activities and increased transmembrane flux of divalent cations, are found at low or sub-micellar concentrations (Coleman et al., 1980; Noh and Gilliland, 1993).

Several electron microscopic studies showed cell surface damage and interior deformities in bacterial cells caused by bile salts (Ruiz et al., 2007; Merritt and Donaldson, 2009). This study

\section{REFERENCES}

Acton, D. S., Plat-Sinnige, M. J., van Wamel, W., de Groot, N., and van Belkum, A. (2009). Intestinal carriage of Staphylococcus aureus: how does its frequency compare with that of nasal carriage and what is its clinical impact? Eur. J. Clin. Microbiol. Infect. Dis. 28, 115-127. doi: 10.1007/s10096-008-0602-7

Bauer, T. M., Steinbruckner, B., Brinkmann, F. E., Ditzen, A. K., Schwacha, H., Aponte, J. J., et al. (2001). Small intestinal bacterial overgrowth in patients with cirrhosis: prevalence and relation with spontaneous bacterial peritonitis. Am. J. Gastroenterol. 96, 2962-2967. doi: 10.1111/j.1572-0241.2001.04668.x

Baumler, A. J., and Sperandio, V. (2016). Interactions between the microbiota and pathogenic bacteria in the gut. Nature 535, 85-93. doi: 10.1038/nature18849

Begley, M., Gahan, C. G., and Hill, C. (2005). The interaction between bacteria and bile. FEMS Microbiol. Rev. 29, 625-651. doi: 10.1016/j.femsre.2004.09.003

Bhairi, S. M., and Mohan, C. (2007). Detergents: A Guide to the Uses and Properties of Detergents in Biological Systems. San Diego, CA: EMD Biosciences, 1-42. demonstrated severe morphological changes, both at the surface and interior, following exposure to unconjugated bile salts at their MIC, and conjugated bile salts at $20 \mathrm{mM}$. It is likely that bile salts at sub-inhibitory concentrations exhibit bacteriostatic action through dissipation of the $\mathrm{pH}$ gradient and loss of transmembrane electric potential. At higher concentrations (MIC), our results suggest the bactericidal action is caused by membrane damage and leakage of intracellular contents.

Thus bile salts have multiple physiological routes by which they can inhibit $S$. aureus growth. Bile salt based derivatives, specifically a CA analog, has recently been utilized in developing novel cationic steroid antibiotics and can be used to treat topical multidrug resistant bacterial infections (Moscoso et al., 2014). This highlights their potential as novel antibacterial agents. Chemical synthesis of various analogs of bile salts utilizing specific physicochemical characteristics in their structure has begun to develop novel antibiotics to combat important bacterial pathogens (Moscoso et al., 2014).

\section{AUTHOR CONTRIBUTIONS}

Conceived and designed the experiments: THS and SRC. Performed the experiments: THS. Analyzed the data: THS, PAL, and SRC. Contributed to reagents/materials/analysis tools: THS, PAL, and SRC. Wrote paper: THS, PAL, and SRC. Critical revision for important intellectual content: THS, PAL, and SRC.

\section{ACKNOWLEDGMENTS}

We thank Felix Trust for providing Ph.D. studentship to THS, and the Centre for Advanced Microscopy facility at University of Reading for assisting with electron microscopy.

\section{SUPPLEMENTARY MATERIAL}

The Supplementary Material for this article can be found online at: http://journal.frontiersin.org/article/10.3389/fmicb. 2017.01581/full\#supplementary-material

Bhalla, A., Aron, D. C., and Donskey, C. J. (2007). Staphylococcus aureus intestinal colonization is associated with increased frequency of $S$. aureus on skin of hospitalized patients. BMC Infect. Dis. 7:105. doi: 10.1186/1471-2334-7-105

Breeuwer, P., Drocourt, J. L., Rombouts, F. M., and Abee, T. (1996). A novel method for continuous determination of the intracellular $\mathrm{pH}$ in bacteria with the internally conjugated fluorescent probe 5 (and 6-)-carboxyfluorescein succinimidyl ester. Appl. Environ. Microbiol. 62, 178-183.

Cantafora, A., Dibiase, A., Angelico, M., and Alvaro, D. (1987). Study of biologically relevant physical-chemical properties of bile-salts by reversephase liquid-chromatography. Chromatographia 24, 277-281. doi: 10.1007/ Bf02688489

Carey, M. C. (1984). Bile acids and bile salts: ionization and solubility properties. Hepatology 4(5 Suppl.), 66-71. doi: 10.1002/hep.1840040812

Chang, C. S., Chen, G. H., Lien, H. C., and Yeh, H. Z. (1998). Small intestine dysmotility and bacterial overgrowth in cirrhotic patients with spontaneous bacterial peritonitis. Hepatology 28, 1187-1190. doi: 10.1002/hep.510280504 
Cheng, J. T., Hale, J. D., Elliot, M., Hancock, R. E., and Straus, S. K. (2009). Effect of membrane composition on antimicrobial peptides aurein 2.2 and 2.3 from Australian southern bell frogs. Biophys. J. 96, 552-565. doi: 10.1016/j.bpj.2008. 10.012

Coleman, R., Lowe, P. J., and Billington, D. (1980). Membrane lipid composition and susceptibility to bile salt damage. Biochim. Biophys. Acta 599, 294-300. doi: 10.1016/0005-2736(80)90075-9

Darkoh, C., Lichtenberger, L. M., Ajami, N., Dial, E. J., Jiang, Z. D., and DuPont, H. L. (2010). Bile acids improve the antimicrobial effect of rifaximin. Antimicrob. Agents Chemother. 54, 3618-3624. doi: 10.1128/AAC.00161-10

Elkins, C. A., and Mullis, L. B. (2004). Bile-mediated aminoglycoside sensitivity in Lactobacillus species likely results from increased membrane permeability attributable to cholic acid. Appl. Environ. Microbiol. 70, 7200-7209. doi: 10.1128/AEM.70.12.7200-7209.2004

Faden, H., Lesse, A. J., Trask, J., Hill, J. A., Hess, D. J., Dryja, D., et al. (2010). Importance of colonization site in the current epidemic of staphylococcal skin abscesses. Pediatrics 125:e618-24. doi: 10.1542/peds.2009-1523

Harrison, F., Roberts, A. E., Gabrilska, R., Rumbaugh, K. P., Lee, C., and Diggle, S. P. (2015). A 1,000-year-old antimicrobial remedy with antistaphylococcal activity. mBio 6:e01129. doi: 10.1128/mBio.01129-15

Horsburgh, M. J., Aish, J. L., White, I. J., Shaw, L., Lithgow, J. K., and Foster, S. J. (2002). sigmaB modulates virulence determinant expression and stress resistance: characterization of a functional $r s b \mathrm{U}$ strain derived from Staphylococcus aureus 8325-4. J. Bacteriol. 184, 5457-5467. doi: 10.1128/JB.184. 19.5457-5467.2002

Ioannou, C. J., Hanlon, G. W., and Denyer, S. P. (2007). Action of disinfectant quaternary ammonium compounds against Staphylococcus aureus. Antimicrob. Agents Chemother. 51, 296-306. doi: 10.1128/AAC.00375-06

Itoh, M., Wada, K., Tan, S., Kitano, Y., Kai, J., and Makino, I. (1999). Antibacterial action of bile acids against Helicobacter pylori and changes in its ultrastructural morphology: effect of unconjugated dihydroxy bile acid. J. Gastroenterol. 34, 571-576. doi: / 10.1007/s005350050374

Kamp, F., Hamilton, J. A., Kamp, F., Westerhoff, H. V., and Hamilton, J. A. (1993). Movement of fatty acids, fatty acid analogues, and bile acids across phospholipid bilayers. Biochemistry 32, 11074-11086. doi: 10.1021/bi00092a017

Kernbauer, E., Maurer, K., Torres, V. J., Shopsin, B., and Cadwell, K. (2015). Gastrointestinal dissemination and transmission of Staphylococcus aureus following bacteremia. Infect. Immun. 83, 372-378. doi: 10.1128/IAI.02272-14

Kluytmans, J. A., and Wertheim, H. F. (2005). Nasal carriage of Staphylococcus aureus and prevention of nosocomial infections. Infection 33, 3-8. doi: 10.1007/ s15010-005-4012-9

Kurdi, P., Kawanishi, K., Mizutani, K., and Yokota, A. (2006). Mechanism of growth inhibition by free bile acids in lactobacilli and bifidobacteria. J. Bacteriol. 188, 1979-1986. doi: 10.1128/JB.188.5.1979-1986.2006

Lindberg, E., Adlerberth, I., Matricardi, P., Bonanno, C., Tripodi, S., Panetta, V., et al. (2011). Effect of lifestyle factors on Staphylococcus aureus gut colonization in Swedish and Italian infants. Clin. Microbiol. Infect. 17, 1209-1215. doi: 10.1111/j.1469-0691.2010.03426.x

Lorenzo-Zuniga, V., Bartoli, R., Planas, R., Hofmann, A. F., Vinado, B., Hagey, L. R., et al. (2003). Oral bile acids reduce bacterial overgrowth, bacterial translocation, and endotoxemia in cirrhotic rats. Hepatology 37, 551-557. doi: 10.1053/jhep.2003.50116

Masaki, H., Asoh, N., Watanabe, H., Tao, M., Watanabe, K., Ikeda, H., et al. (2003). Possible relationship between Staphylococcus aureus colonizing the respiratory tract and rectum and $S$. aureus isolated in a geriatric hospital environment. Intern. Med. 42, 281-282. doi: 10.2169/internalmedicine.42.281

Merritt, M. E., and Donaldson, J. R. (2009). Effect of bile salts on the DNA and membrane integrity of enteric bacteria. J. Med. Microbiol. 58(Pt 12), 1533-1541. doi: 10.1099/jmm.0.014092-0

Moscoso, M., Esteban-Torres, M., Menendez, M., and Garcia, E. (2014). In vitro bactericidal and bacteriolytic activity of ceragenin CSA-13 against planktonic cultures and biofilms of Streptococcus pneumoniae and other pathogenic streptococci. PLoS ONE 9:e101037. doi: 10.1371/journal.pone.0101037

Nelson, M. L., Grier, M. C., Barbaro, S. E., and Ismail, M. Y. (2009). Polyfunctional antibiotics affecting bacterial membrane dynamics. Antiinfect. Agents Med. Chem. 8, 3-16. doi: 10.2174/187152109787047779
Noh, D. O., and Gilliland, S. E. (1993). Influence of bile on cellular integrity and beta-galactosidase activity of Lactobacillus acidophilus. J. Dairy Sci. 76, 1253-1259. doi: 10.3168/jds.S0022-0302(93)77454-8

Peacock, S. J., de Silva, I., and Lowy, F. D. (2001). What determines nasal carriage of Staphylococcus aureus? Trends Microbiol. 9, 605-610.

Prieto, A. I., Ramos-Morales, F., and Casadesus, J. (2004). Bile-induced DNA damage in Salmonella enterica. Genetics 168, 1787-1794. doi: 10.1534/genetics. 104.031062

Quigley, E. M. (2013). Gut bacteria in health and disease. Gastroenterol. Hepatol. 9, 560-569.

Roda, A., Hofmann, A. F., and Mysels, K. J. (1983). The influence of bile salt structure on self-association in aqueous solutions. J. Biol. Chem. 258, 6362-6370.

Ruiz, L., Sanchez, B., Ruas-Madiedo, P., de Los Reyes-Gavilan, C. G., and Margolles, A. (2007). Cell envelope changes in Bifidobacterium animalis ssp. lactis as a response to bile. FEMS Microbiol. Lett. 274, 316-322. doi: 10.1111/j. 1574-6968.2007.00854.x

Russell, J. B. (1991). Resistance of Streptococcus bovis to acetic acid at low pH: relationship between intracellular $\mathrm{pH}$ and anion accumulation. Appl. Environ. Microbiol. 57, 255-259.

Salmond, C. V., Kroll, R. G., and Booth, I. R. (1984). The effect of food preservatives on $\mathrm{pH}$ homeostasis in Escherichia coli. J. Gen. Microbiol. 130, 2845-2850. doi: 10.1099/00221287-130-11-2845

Sannasiddappa, T. H., Hood, G. A., Hanson, K. J., Costabile, A., Gibson, G. R., and Clarke, S. R. (2015). Staphylococcus aureus MnhF mediates cholate efflux and facilitates survival under human colonic conditions. Infect. Immun. 83, 2350-2357. doi: 10.1128/IAI.00238-15

Scholmerich, J., Becher, M. S., Schmidt, K., Schubert, R., Kremer, B., Feldhaus, S., et al. (1984). Influence of hydroxylation and conjugation of bile salts on their membrane-damaging properties-studies on isolated hepatocytes and lipid membrane vesicles. Hepatology 4, 661-666. doi: 10.1002/hep.184004 0416

Sekirov, I., and Finlay, B. B. (2009). The role of the intestinal microbiota in enteric infection. J. Physiol. 587(Pt 17), 4159-4167. doi: 10.1113/jphysiol.2009.17 2742

Squier, C., Rihs, J. D., Risa, K. J., Sagnimeni, A., Wagener, M. M., Stout, J., et al. (2002). Staphylococcus aureus rectal carriage and its association with infections in patients in a surgical intensive care unit and a liver transplant unit. Infect. Control Hosp. Epidemiol. 23, 495-501. doi: 10.1086/50 2095

Sung, J. Y., Shaffer, E. A., and Costerton, J. W. (1993). Antibacterial activity of bile salts against common biliary pathogens. Effects of hydrophobicity of the molecule and in the presence of phospholipids. Dig. Dis. Sci. 38, 2104-2112. doi: 10.1007/BF01297092

Tong, S. Y., Davis, J. S., Eichenberger, E., Holland, T. L., and Fowler, V. G. (2015). Staphylococcus aureus infections: epidemiology, pathophysiology, clinical manifestations, and management. Clin. Microbiol. Rev. 28, 603-661. doi: 10.1128/CMR.00134-14

Wertheim, H. F., Vos, M. C., Ott, A., van Belkum, A., Voss, A., Kluytmans, J. A., et al. (2004). Risk and outcome of nosocomial Staphylococcus aureus bacteraemia in nasal carriers versus non-carriers. Lancet 364, 703-705. doi: 10.1016/S0140-6736(04)16897-9

Zhang, Y. J., Li, S., Gan, R. Y., Zhou, T., Xu, D. P., and Li, H. B. (2015). Impacts of gut bacteria on human health and diseases. Int. J. Mol. Sci. 16, 7493-7519. doi: $10.3390 /$ ijms 16047493

Conflict of Interest Statement: The authors declare that the research was conducted in the absence of any commercial or financial relationships that could be construed as a potential conflict of interest.

Copyright (c) 2017 Sannasiddappa, Lund and Clarke. This is an open-access article distributed under the terms of the Creative Commons Attribution License (CC BY). The use, distribution or reproduction in other forums is permitted, provided the original author(s) or licensor are credited and that the original publication in this journal is cited, in accordance with accepted academic practice. No use, distribution or reproduction is permitted which does not comply with these terms. 